\title{
Altered Development of the Dorsolateral Prefrontal Cortex in Chromosome 22q11.2 Deletion Syndrome: an in vivo ${ }^{1} \mathrm{H}$ Spectroscopy study
}

\author{
Vandana Shashi ${ }^{1,2}$, Aravindhan Veerapandiyan ${ }^{3}$, Matcheri S. Keshavan ${ }^{4}$, Michael \\ Zapadka $^{2}$, Kelly Schoch ${ }^{1}$, Thomas R. Kwapil ${ }^{5}$, Stephen R. Hooper ${ }^{6}$, and Jeffrey A. Stanley ${ }^{7}$ \\ ${ }^{1}$ Duke University Medical Center, Division of Medical Genetics \\ ${ }^{2}$ Wake Forest University Health Sciences \\ ${ }^{3}$ Duke University Medical Center, Division of Pediatric Neurology \\ ${ }^{4}$ Harvard Medical School, Beth Israel Deaconess Medical Center \\ 5 University of North Carolina at Greensboro \\ ${ }^{6}$ University of North Carolina School of Medicine \\ ${ }^{7}$ Wayne State University School of Medicine
}

\begin{abstract}
Background-Chromosome 22q11.2 deletion syndrome (22q11DS), the most common microdeletion in humans, is associated with multiple medical features, almost universal cognitive deficits, and a high-risk of schizophrenia. The metabolic basis of the psychological/psychiatric features is not well understood. Volumetric brain imaging studies have shown that gray matter abnormalities in the dorsolateral prefrontal cortex (DLPFC), an area that is believed to be integral for higher neurocognition, as well as being involved in schizophrenia, are associated with the psychological manifestations. However, studies have not characterized any possible metabolite alterations within the DLPFC of children with 22q11DS and their correlations with the psychological findings.
\end{abstract}

Methods-We conducted a short echo-time, single-voxel, in vivo ${ }^{1} \mathrm{H}$ spectroscopy study involving children with 22q11DS $(n=26)$ and matched control subjects $(n=23)$.

Results-Absolute N-acetyl-aspartate (NAA) levels from the DLPFC were significantly elevated in children with 22q11DS compared to control subjects and the elevations were associated with poor global functioning and higher rates of comorbid attention deficit hyperactivity disorder. Children with 22q11DS had a lack of an age-associated decrease in NAA levels, a trend seen in the control subjects. However, the results did not remain statistically significant after corrections for multiple comparisons were made.

C 2012 Society of Biological Psychiatry. Published by Elsevier Inc. All rights reserved.

Corresponding author: Vandana Shashi, MD, Associate Professor of Pediatrics, Division of Medical Genetics, Duke University Medical Center, vandana.shashi@ duke.edu, Phone: 919-684-2036, Fax: 919-684-8944.

Publisher's Disclaimer: This is a PDF file of an unedited manuscript that has been accepted for publication. As a service to our customers we are providing this early version of the manuscript. The manuscript will undergo copyediting, typesetting, and review of the resulting proof before it is published in its final citable form. Please note that during the production process errors may be discovered which could affect the content, and all legal disclaimers that apply to the journal pertain.

Financial Disclosures

The authors report no biomedical financial interests or potential conflicts of interest. 
Conclusion-These findings represent the first report of ${ }^{1} \mathrm{H}$ spectroscopy in children with 22q11DS. The elevated DLPFC NAA levels and the lack of decreasing trends in NAA with age in the 22q11DS group relative to controls suggest an alteration in cortical development. Also, such neuronal dysmaturation is associated with psychopathology in children with 22q11DS.

\section{Keywords}

Chromosome 22q11.2 deletion syndrome; velocardiofacial syndrome; DiGeorge syndrome; neuropsychology; ADHD; ${ }^{1} \mathrm{H}$ MRS; spectroscopy; $\mathrm{N}$-acetyl-aspartate; NAA

\section{Introduction}

Chromosome 22q11.2 deletion syndrome (22q11DS), also known as DiGeorge syndrome or velocardiofacial syndrome, is the most common chromosomal microdeletion syndrome in humans, occurring in approximately 1 in 1600 live births (1, 2). It is associated with numerous and variable clinical manifestations, the more common of which are conotruncal heart abnormalities, palatal anomalies, hypoparathyroidism, and immune deficiency. Cognitive problems are seen in $80-100 \%$ of affected individuals, are highly variable, with deficits in visual-spatial processing, executive function, attention, verbal learning, working memory, arithmetic performance, language and impaired functionality (3-5). Behavioral and emotional problems occur in about 50\% of children with 22q11DS; the most common are attention deficit/hyperactivity (ADHD), social impairments, somatic complaints, and anxiety problems (5-8). 22q11DS is also the most common identifiable genetic risk factor for schizophrenia; at least $25 \%$ of individuals with this deletion develop a schizophrenia-like psychosis by young adulthood (9). The exact pathophysiology of the cognitive/behavioral/ emotional/psychiatric manifestations of the condition remains unexplained, although undoubtedly the hemizygous deletion of several genes predisposes to these deficits.

In attempts to quantify the structural correlates of the neurocognitive manifestations, brain imaging studies have delineated several areas of gray matter volumetric reductions in individuals with 22q11DS, mainly in the posterior cortical regions and the cerebellum (10). An area of special interest is the left dorsolateral prefrontal cortex (DLPFC) which, together with its other cortical and subcortical circuits, plays an important role in attention, working memory, planning, reasoning, and execution (deficits that are integral to the neurocognitive phenotype in 22q11DS) $(11,12)$.

Voxel based morphometric studies have shown volumetric reduction in the DLPFC grey matter volume in individuals with 22q11DS $(13,14)$; this reduction is associated with deficits in sustained attention and executive function (14) and may be predictive of risk for schizophrenia-like psychotic symptoms in these patients in later life. Nonetheless, it is also evident that relative to other brain regions, the frontal lobes show less volumetric reduction in children with 22q11DS $(14,15)$. This may suggest an alteration in the normal pruning of overproduced synaptic connections, which in the DLPFC occurs in adolescence (16-20). Thus, it is possible that pruning may occur later in children with 22q11DS than in typically developing children (10) and the delayed change in morphology of the frontal lobes may be associated with some of the neurocognitive abnormalities in the condition (14).

Further investigation using noninvasive neurochemical imaging techniques such as in-vivo proton magnetic resonance spectroscopy $\left({ }^{1} \mathrm{H}\right.$ MRS) could yield important information about the brain developmental alterations, but such studies are lacking in children with 22q11DS. ${ }^{1} \mathrm{H}$ MRS allows for the in-vivo analysis of neurometabolite levels such as $\mathrm{N}$ acetyl-aspartate (NAA), a neurometabolite present almost exclusively in the nervous system $(21,22)$ and is sensitive to brain development. In cortical areas, NAA increases with age, 
with changes most prominent in early postnatal development $(23,24)$, followed by decreases in prefrontal NAA levels in adolescence and early adulthood (25-27). Collectively, the increase followed by decreasing NAA levels with age in the prefrontal cortex may reflect the overproduction of dendrites and synaptic terminals followed by the normal pruning of synapses that occur during cortical brain maturation $(20,26,28,29)$, although conclusive evidence is lacking. In contrast, NAA levels have been reported as being relatively stable or increasing linearly with age in white matter tissue during brain development $(26,30)$. Therefore, NAA is believed to be a marker of functioning neurons or more specifically in the context of development a marker of cortical maturation (29). NAA has been measured in several neurological and psychiatric disorders, with the aim of understanding the pathophysiology of the particular disorder, including ADHD, wherein considerable variability in neurometabolites has been reported (31). To our knowledge, there have been no studies so far that have reported neurometabolite findings in DLPFC in children with 22q11DS. One recent study of ${ }^{1} \mathrm{H}$ MRS in adults with 22q11DS found no differences in DLPFC metabolites between individuals with and without schizophrenia (32).

${ }^{1} \mathrm{H}$ MRS studies in individuals with schizophrenia in the general population have consistently reported decreased NAA within several brain regions, including the left DLPFC (both gray and white matter) in individuals with chronic schizophrenia and not in most firstepisode studies $(33,34)$. Decreased NAA in the DLPFC may suggest a reduction in functioning neurons in the cortex (27). A few ${ }^{1} \mathrm{H}$ MRS studies in individuals at high-risk for schizophrenia (other than 22q11DS) have shown varying reductions of NAA in prefrontal areas $(27,35)$ and one reported increased NAA in prefrontal white matter in these individuals (36) but a recent meta-analysis reported that there were no NAA abnormalities in the frontal areas in individuals at high-risk (offspring of individuals with schizophrenia) in the general population (33). Thus, there are no specific trends in the neurometabolites in these individuals at high-risk for schizophrenia.

The aim of the current study is to investigate possible neurometabolite alterations in the DLPFC of nonpsychotic children with 22q11DS compared to healthy controls and to determine the neuropsychological correlates of these neurometabolites prior to the onset of psychosis. Additionally, due to significant changes in ${ }^{1} \mathrm{H}$ metabolite levels with age in typically developing individuals, possible age effects are also investigated. Based on our previous findings of a correlation between DLPFC gray matter volumetric reduction and neurocognition (14), as well as strong empirical evidence that the left DLPFC is involved in schizophrenia and is abnormal in individuals at high risk for the disorder $(27,34,37,38)$, we hypothesized that our cohort of children with 22q11DS (at high-risk of psychosis) would show reduced NAA in the left DLPFC and that the reduced NAA would be correlated with neuropsychological functioning.

\section{Methods}

This cross-sectional study was approved by the Institutional Review Board of Wake Forest University Health Sciences. Participants included 26 patients with 22q11DS and 23 healthy control subjects. The 22q11DS subjects were enrolled in the study through the Genetics clinic at Wake Forest University and the control subjects were recruited through the local pediatric practices and public school systems. The 22q11DS and control subjects were matched for age and gender. They were not matched for handedness, but there were no significant differences in handedness between the two groups $\left(X^{2}=002, p=.96\right)$. Exclusion criteria for both groups were a psychotic disorder, and age above 16 years; for the control subjects, the presence of a neurodevelopmental or genetic disorder. All children with 22q11DS had a molecularly confirmed deletion of the 22q11.2 interval, with either 
fluorescence in-situ hybridization (Vysis, Gaithersburg, MD) or microarray analyses (Affymetrix, www.affymetrix.com).

\section{Neuropsychological measures}

The participants underwent a battery of neuropsychological tests; parental interviews were also conducted. These included the Wechsler Intelligence Scale for Children (WISC-IV) (39); earlier participants were administered the WISC-III (40), Wechsler Individual Achievement Test (WIAT-II) (41), Wisconsin Cart Sorting Test (42), Continuous Performance Test, IP and AX conditions (43) and the Computerized Diagnostic Interview Schedule for Children (C_DISC) (44). Global assessment of functioning by an examiner rated scale (GAF) was also ascertained for all participants, providing ratings of overall function, independent of specific mental health diagnoses (45).

\section{Single-Voxel ${ }^{1} \mathrm{H}$ Spectroscopy}

MRIs were conducted with a 1.5 T GE Signa imaging system (GE Medical Systems, Milwaukee, WI). A set of sagittal and axial scout images were first obtained to ascertain subject position and quality of images. A 3D spoiled gradient recalled acquisition (TR=25 $\mathrm{ms}, \mathrm{TE}=5 \mathrm{~ms}$, flip angle $=400, \mathrm{FOV}=240 \times 180 \mathrm{~mm}$, slice thickness $=1.5 \mathrm{~mm}$, matrix $=256 \times 192$ ), was performed in the coronal plane to obtain 124 images covering the entire brain for tissue segmentation. $\mathrm{A}$ fast spin echo sequence $(2 \mathrm{D}$ fast spin-echo, TR= $2,500 \mathrm{~ms}$, TE2 $=17 / 102 \mathrm{~ms}$, echo-train length $=8, \mathrm{FOV}=240 \mathrm{~mm}^{2}$, with 24 slices, slice thickness $=5 \mathrm{~mm}$, gap $=0 \mathrm{~mm}, \mathrm{NEX}=1$, matrix $=256 \times 192$ ) was also obtained for $\mathrm{T}_{2}$ and proton density images in the coronal plane. Based on the scout images, a $2.0 \times 2.0 \times 2.0 \mathrm{~cm}^{2}$ voxel was placed in the left DLPFC to acquire the in vivo singe-voxel, short-echo time (TE) ${ }^{1} \mathrm{H}$ spectroscopy using the point-resolved spectroscopy sequence (PRESS) and the following parameters: $\mathrm{TE}=35 \mathrm{~ms}$, $\mathrm{TR}=1,500 \mathrm{~ms}$, bandwidth $=2 \mathrm{kHz}, 2048$ complex data points and 128 acquisitions. The superior frontal sulcus, the lateral fissure, and the genu of the corpus callosum were used as anatomical boundaries for the voxel placement in the DLPFC (Figure 1). Water unsuppressed spectra were also acquired for spectral line shape correction (46) and for absolute quantification of ${ }^{1} \mathrm{H}$ metabolite levels with $\mathrm{mmol} / \mathrm{kg}$ wet weight units. The ${ }^{1} \mathrm{H}$ metabolites, Glutamate (Glu), glutamine (Gln), myoinositol, cholinecontaining compounds $(\mathrm{GPC}+\mathrm{PC})$, phosphocreatine plus creatine $(\mathrm{PCr}+\mathrm{Cr})$, NAA, N-acetylaspartylglutamate (NAAG), as well as taurine, alanine, aspartate, gamma-amino-butyric acid (GABA), glucose, and lipid resonances and macromolecule resonances (47) were quantified using the Linear Combination (LC) Model software (48), an operator-independent fitting routine. The ${ }^{1} \mathrm{H}$ metabolites with reasonable level of fitting confidence [i.e., the metabolites with an overall mean Cramer-Rao Lower Bound (CRLB) value of less than 20\%] were the dependent variables in this analysis and included NAA, $\mathrm{PCr}+\mathrm{Cr}$, GPC+PC, myoinositol and glutamate. To address the variability in the tissue composition within the voxels of interest, the proportions of gray matter (GM), white matter (WM), and cerebrospinal fluid (CSF) were estimated for each localized ${ }^{1} \mathrm{H}$ spectroscopy voxel. In a fully automated procedure, the $\mathrm{T}_{1}$-weighted images were corrected for any $\mathrm{B}_{1}$ field bias followed by extracting the brain tissue and segmenting the images into partial volume maps of GM, WM, and CSF space using FSL tools (49). The tissue fractions within the voxels of interest were then extracted from the segmented images by matching the coordinates of the ${ }^{1} \mathrm{H}$ spectroscopy voxel with the images using the FSL tools. The GM, WM, and CSF voxel content values, along with the other appropriate relaxation correction factors (23), were then utilized to obtain absolute quantification values, as described elsewhere (50).

\section{Statistical methods}

Statistical tests were performed with SPSS version 18.0, with independent sample t-tests or univariate analysis of variance for continuous variables and Fisher's exact test for 
categorical variables to examine the differences in neuropsychological functioning between the two groups. The group differences in NAA, $\mathrm{PCr}+\mathrm{Cr}, \mathrm{GPC}+\mathrm{PC}$, glutamate and myoinositol levels were examined with independent samples t-tests. Medication status, age and gender were used as covariates in univariate analyses of variance to determine if the results of the group differences were influenced by these factors. Pearson correlations were computed to determine associations between the neurometabolites and psychological functioning. Although our analyses were based on an a priori hypothesis, we present data before and after statistical corrections for multiple comparisons, although some studies involving 22q11DS do not adopt such corrections (32). To assess age effects, a group-byage interaction model was also included.

\section{Results \\ Demographics}

There were no significant differences in age, gender, ethnicity or parental socioeconomic status between the 22q11DS and control groups. The patient and control groups did not differ on sex composition (65\% male and 54\% male respectively, ethnic composition (92\% Caucasian, 8\% African American and 84\% Caucasian, 8\% African American and 8\% Hispanic respectively), age (10.9 \pm 2.6 years and $11 . \pm 2.2$ years respectively), handedness $\left(\mathrm{X}^{2}=.004, \mathrm{p}=.99\right)$, or socio-economic status (SES in 22q11DS group $=32.8(13.1)$ and SES in control group $=30.5$ (12.3). Medications in the 22q11DS and control groups consisted of stimulants for ADHD and anxiolytics, with 8/26 children with 22q11DS and 7/23 control children on a medication, with no significant group differences (Fisher's exact test $\mathrm{p}=1.0$ ).

\section{Neuropsychological Measures}

The 22q11DS exhibited poorer neuropsychological performance than the control groups with significant differences in verbal comprehension, perceptual organization, working memory, processing speed, achievement, sustained attention, executive function and verbal learning (Table 1) (some data previously published) (4). There was no difference in the incidence of anxiety and AD/HD between the two groups. None of the subjects had a psychotic illness at the time of the study.

\section{Neurometabolites and overall quality of the ${ }^{1} \mathrm{H}$ MRS}

Figure 1 includes the spectral modeling using LC Model of a typical in vivo ${ }^{1} \mathrm{H}$ spectrum from the left DLPFC. The mean full-width half maximum (FWHM) of the NAA for 22q11DS and controls were $2.7 \pm 0.7 \mathrm{~Hz}$ and $2.5 \pm 0.6 \mathrm{~Hz}$, and the mean signal-to-noise ratios were 10.0 \pm 1.6 and $9.9 \pm 1.8$, respectively; both were non-significant. The mean Cramer-Rao Lower Bound values of NAA, NAA+NAAG, glutamate, glutamate+glycine, myo-inositol, $\mathrm{PCr}+\mathrm{Cr}$ and $\mathrm{GPC}+\mathrm{PC}$ are noted in Table 2. Additionally, there were no significant differences in gray matter fraction within the ${ }^{1} \mathrm{H}$ spectroscopy voxel, between the 22q11DS and control groups, as presented in Table 2. NAA levels were significantly higher in the 22q11DS group, relative to the control group and this group difference in NAA remained significant when ADHD medication status was used as a covariate (Univariate analysis of variance, $\mathrm{F}=4.5, \mathrm{p}<0.05$ ) as well as using age, gender as covariates (Univariate analysis of variance, $\mathrm{F}=4.1, \mathrm{p}<.05)$. Other neurometabolites did not significantly differ between the two groups.

\section{Age Effects}

There were no significant correlations with age for the metabolites except for myo-inositol, which was negatively correlated with age in the 22q11DS group (Pearson $r=-0.47, p<0.05$ ) but not in the control group (Pearson $\mathrm{r}=0.20, \mathrm{p}=0.35$ ). The control group showed a trend 
towards decreasing NAA levels with age, although not significant (Pearson $\mathrm{r}=-0.32$, medium effect size), which was absent in the 22q11DS group ( $\mathrm{r}=-0.030)$. The relationship between age and NAA levels in the two groups is illustrated in Figure 2.

We divided the 22q11DS children and the control subjects in two groups based on the median age in each group (10.6 years in the 22q11DS group and 11.1 years in the control group). A significantly higher mean NAA level was seen in younger control subjects, compared to the older ones [11.16(0.96) and 10.22(0.65) respectively, $t$ statistic $=2.60$, $\mathrm{p}<0.05]$. There was no significant difference in the mean NAA levels in children with 22q11DS who were above and below the median age 11.29(.93) and 11.31(.93) respectively. There was also a significantly higher mean NAA level in older children with 22q11DS relative to older controls [11.29 (0.93) and $10.27(0.64)$ respectively, $F=9.3, p<.01$. In contrast the NAA levels were not significantly different between the younger 22q11DS and control children [11.31(0.93) and 10.27(0.64)] respectively. These results confirm the divergence in NAA levels with increasing age, as illustrated in figure 2.

When Bonferroni corrections were applied due to the multiple comparisons that were used, the differences in the groups and age on NAA and myoinositol levels were no longer significant.

\section{Relationship between neuropsychological functioning and NAA levels}

We then examined the relationship between NAA levels and neuropsychological functioning, since NAA differed between the two groups. A significant relationship was found between NAA and global functioning (GAF) in the 22q11DS group (Table 3 and Figure 3). The interaction term of group by NAA was not significant for GAF scores. The mean NAA level was significantly higher in children with 22q11DS who had ADHD, compared to those that did not have this diagnosis (Table 3). No such relationships between ADHD diagnosis, GAF or other neuropsychological measures and NAA levels were evident in the control group. In order to account for the effects of ADHD medication upon the correlation between NAA and global functioning, we performed Pearson partial correlations with ADHD medications as a covariate and found that the correlations between NAA levels and GAF $(r=-0.43, p<0.05)$ remained significant. We did not find a significant correlation between full-scale IQ, verbal comprehension or perceptual organization indices and NAA levels in either the 22q11DS or control groups.

\section{Discussion}

To our knowledge, this is the first study of ${ }^{1} \mathrm{H}$ spectroscopy findings in children with 22q11DS. In contradiction to our hypothesis, mean absolute NAA level in the left DLPFC in our cohort of 22q11DS patients was higher than in the control group, with decreasing NAA levels with age in the control group, but not in the 22q11DS group. Although the results were not significant once corrections for multiple comparisons were applied, the evidence is suggestive that the developmental trajectory of NAA levels may be different in the two groups.

NAA, which is the second most abundant free amino acid in the brain next to glutamate, is synthesized in neuronal mitochondria from acetyl-CoA and aspartate by the membrane bound enzyme L-aspartate $\mathrm{N}$-acetyltransferase and the principal metabolizing enzyme, $\mathrm{N}$ acetyl-L-aspartate aminohydrolase II (aspartoacylase), is primarily localized in white matter with highest activity in oligodendrocytes (51). This is consistent with cell culture studies showing that NAA is localized in both neurons, oligodendrocytes and in O-2A progenitor cells $(52,53)$ and provides evidence of inter-compartmental cycling of NAA between neurons and oligodendrocytes $(51,52,54)$. Thus, NAA may be a marker of functioning 
neuroaxonal tissue that includes functional aspects of the formation and/or maintenance of myelin (54). However, in the context of brain development NAA levels do show dynamic age-related changes. Early in postnatal brain development, cortical NAA levels are low; NAA dramatically increases in early postnatal development $(23,24)$, reaches a plateau in later childhood/early adolescence followed by decreasing levels in late adolescence and early adulthood (i.e., similar to an inverted "U" trajectory) (25-27, 30). Specifically, the brain regions showing greatest NAA elevations during development include the cortical gray matter, cerebellum and the thalamus (30). This provides additional evidence that NAA does not merely reflect the number of neurons but is a marker of functioning neurons. Additionally, in the context of development, the timing of the inverted " $U$ " trajectory of NAA is consistent with the temporal maturation of the prefrontal cortex $(29,30,55)$. Therefore, the non-progressive decreasing NAA levels in 22q11DS compared to controls suggest a developmental deviation in 22q11DS. The decreasing myo-Inositol with age in $22 q 11 D S$ contrasted by age invariant changes in controls suggests there is decreasing glial content in 22 q11DS, which may or may not be related to the lack of synaptic pruning. Interestingly, low levels of myo-Inositol have been reported in individuals with longstanding schizophrenia, thought to be related to reduced glial activity (56). Further investigation is warranted.

Our finding of higher NAA levels within the DLPFC could be a sensitive indicator of neuropathology in 22q11DS, since NAA is an indicator of neuronal integrity, whereas volumetric studies are an indirect indicator of underlying neuronal pathology, with gray matter consisting of a complex combination of neurons with dendrites, synapses, as well as glia and vasculature (17). Further evidence for altered neuronal development in 22q11DS is provided by altered cortical development in children with the condition $(57,58)$. Although the exact cause of the higher NAA in our cohort of children with 22q11DS is unclear, several mechanisms could exist. One possibility is that there is an increase in gray matter neuronal volume within the voxel that we placed in the DLPFC. However, although frontal lobe gray matter volumes are relatively preserved in children with 22q11DS $(14,15,59)$, an actual increase in gray matter in this area has not been reported. An alternate explanation is that the volumetric gray matter reductions within the DLPFC which we reported previously in children with 22q11DS could involve only non-neuronal tissue, with preservation of neuronal tissue or even an excess of it, effectively altering the ratio of neuronal to nonneuronal tissue.

We performed voxel segmentation analyses and there were no group differences in the gray matter tissue percentages and tissue fraction values were then used in the calculation of absolute metabolite concentration levels. Thus, our results reflect gray matter neurometabolite levels and thus would not be reflective of white matter, although white matter volumetric abnormalities are common in 22q11DS $(60,61)$. We did not correlate gray matter volumes in the DLPFC with the NAA levels, since the voxel we placed would not capture all of the DLPFC and additionally, the gray matter composition of the voxel is approximately $50 \%$ and thus valid inferences could not be made about the volume of the DLPFC and the NAA levels. The only other study of brain ${ }^{1} \mathrm{H}$ MRS in individuals with 22q11DS was in a small group of adults, comparing those with schizophrenia to those without and control subjects; there were no significant changes in neurometabolites in the DLPFC between the groups, but interestingly, the authors noticed a trend towards higher levels of neurometabolites in the 22q11DS group without schizophrenia, compared to the healthy controls and 22q11DS individuals with schizophrenia (32) and it was postulated that neurometabolites may be higher in individuals with 22q11DS prior to psychosis and that in the transition towards psychosis the levels of neurometabolites would decrease. Ongoing longitudinal studies on our cohort would enable further examination of this hypothesis. 
Our finding of an increased DLFPC NAA in 22q11DS being related to ADHD and decreased GAF is intriguing. A relative increase in neuronal vs. non-neuronal tissue due to neuronal dysmaturation in children with 22q11DS could be associated with elevated NAA and lower global functioning and higher rates of ADHD. Studies on ADHD in the general population show reduced NAA in prefrontal cortex and an elevated NAA/PCr+Cr ratio (31, 62-64), but the reports are inconsistent, with some studies reporting no abnormalities in prefrontal cortex NAA in association with ADHD (31). The elevation of NAA that we found is more likely to be due to neuronal dysmaturation than a compensatory mechanism to lower neurocognition in children with 22q11DS, since the elevated NAA is associated with lower functionality and ADHD and not with IQ. Delayed cortical maturation is thought to be related to the impulsivity and inattention seen in ADHD in the general population $(65,66)$. Our preliminary report needs to be confirmed in larger cohorts, as well as in a longitudinal manner.

In comparing the findings of our study to those seen in spectroscopy studies of individuals with schizophrenia and those at high-risk for the disorder in the general population, we did not see a reduction in NAA within the DLFPC in children with 22q11DS, who are considered to be at high-risk for schizophrenia in later life. Although this was contrary to our expectation the elevated NAA in our study may be related to abnormalities in brain maturation in 22q11DS. Further longitudinal studies in children with 22q11DS and high-risk individuals in the general population are needed for clarity on the relationship between neurometabolites in the DLPFC and the psychosis risk.

The advantages of our study were that we only had children who were nonpsychotic and thus the effects of psychosis on psychological function and NAA levels were not confounds; our subjects were not recruited from one referral source such as the pediatric cardiology or child psychiatry clinic and thus are representative of the wide spectrum of manifestations seen in 22q11DS.

In conclusion, children with 22q11DS demonstrate elevated levels of NAA in conjunction with higher rates of ADHD and lower global function. The increase in NAA in 22q11DS children may be reflective of relatively preserved neuronal tissue in the DLPFC due to delayed neuronal maturation and synaptic pruning. The relationship between ADHD and global functioning with the NAA levels underscores the importance of alterations of neurometabolites that are not directly related to the deleted genes, but rather a consequence of altered neuronal maturation/structure, in mediating the psychological abnormalities in these children.

\section{Acknowledgments}

This work was supported in part by R01MH78015-04, PI: Shashi, Vandana

\section{References}

1. Shprintzen RJ. Velocardiofacial syndrome. Otolaryngol Clin North Am. 2000; 33:1217-1240. vi. [PubMed: 11449784]

2. Shprintzen RJ. Velo-cardio-facial syndrome: 30 Years of study. Developmental Disabilities Research Reviews. 2008; 14:3-10. [PubMed: 18636631]

3. Golding-Kushner KJ, Weller G, Shprintzen RJ. Velo-cardio-facial syndrome: language and psychological profiles. J Craniofac Genet Dev Biol. 1985; 5:259-266. [PubMed: 4044789]

4. Lewandowski KE, Shashi V, Berry PM, Kwapil TR. Schizophrenic-like neurocognitive deficits in children and adolescents with 22q11 deletion syndrome. Am J MedGenet B Neuropsychiatr Genet. 2007; 144:27-36. 
5. Swillen A, Devriendt K, Legius E, Eyskens B, Dumoulin M, Gewillig M, et al. Intelligence and psychosocial adjustment in velocardiofacial syndrome: a study of 37 children and adolescents with VCFS. J Med Genet. 1997; 34:453-458. [PubMed: 9192263]

6. Feinstein C, Eliez S, Blasey C, Reiss AL. Psychiatric disorders and behavioral problems in children with velocardiofacial syndrome: usefulness as phenotypic indicators of schizophrenia risk. Biol Psychiatry. 2002; 51:312-318. [PubMed: 11958782]

7. Swillen A, Vogels A, Devriendt K, Fryns JP. Chromosome 22q11 deletion syndrome: update and review of the clinical features, cognitive-behavioral spectrum, and psychiatric complications. Am J Med Genet. 2000; 97:128-135. [PubMed: 11180220]

8. Wang PP, Woodin MF, Kreps-Falk R, Moss EM. Research on behavioral phenotypes: velocardiofacial syndrome (deletion 22q11.2). Developmental Medicine and Child Neurology. 2000; 42:422-427. [PubMed: 10875531]

9. Murphy KC, Jones LA, Owen MJ. High rates of schizophrenia in adults with velo-cardio-facial syndrome. Arch Gen Psychiatry. 1999; 56:940-945. [PubMed: 10530637]

10. Tan GM, Arnone D, McIntosh AM, Ebmeier KP. Meta-analysis of magnetic resonance imaging studies in chromosome 22q11.2 deletion syndrome (velocardiofacial syndrome). Schizophr Res. 2009

11. Liang P, Wang Z, Yang Y, Jia X, Li K. Functional disconnection and compensation in mild cognitive impairment: evidence from DLPFC connectivity using resting-state fMRI. PLoS One. 2011; 6:e22153. [PubMed: 21811568]

12. van Veelen NM, Vink M, Ramsey NF, Kahn RS. Left dorsolateral prefrontal cortex dysfunction in medication-naive schizophrenia. Schizophr Res. 2010; 123:22-29. [PubMed: 20724113]

13. Kates WR, Antshel K, Willhite R, Bessette BA, AbdulSabur N, Higgins AM. Gender-moderated dorsolateral prefrontal reductions in 22q11.2 Deletion Syndrome: implications for risk for schizophrenia. Child Neuropsychol. 2005; 11:73-85. [PubMed: 15823984]

14. Shashi V, Kwapil TR, Kaczorowski J, Berry MN, Santos CS, Howard TD, et al. Evidence of gray matter reduction and dysfunction in chromosome 22q11.2 deletion syndrome. Psychiatry Res. 2010; 181:1-8. [PubMed: 19962860]

15. Eliez S, Schmitt JE, White CD, Reiss AL. Children and adolescents with velocardiofacial syndrome: a volumetric MRI study. Am J Psychiatry. 2000; 157:409-415. [PubMed: 10698817]

16. Bourgeois JP, Rakic P. Changes of synaptic density in the primary visual cortex of the macaque monkey from fetal to adult stage. J Neurosci. 1993; 13:2801-2820. [PubMed: 8331373]

17. Gogtay N, Giedd JN, Lusk L, Hayashi KM, Greenstein D, Vaituzis AC, et al. Dynamic mapping of human cortical development during childhood through early adulthood. Proc Natl Acad Sci U S A. 2004; 101:8174-8179. [PubMed: 15148381]

18. Pfefferbaum A, Mathalon DH, Sullivan EV, Rawles JM, Zipursky RB, Lim KO. A quantitative magnetic resonance imaging study of changes in brain morphology from infancy to late adulthood. Arch Neurol. 1994; 51:874-887. [PubMed: 8080387]

19. Purves D, White LE, Riddle DR. Is neural development Darwinian? Trends Neurosci. 1996; 19:460-464. [PubMed: 8931267]

20. Rakic P, Bourgeois JP, Eckenhoff MF, Zecevic N, Goldman-Rakic PS. Concurrent overproduction of synapses in diverse regions of the primate cerebral cortex. Science. 1986; 232:232-235. [PubMed: 3952506]

21. Birken DL, Oldendorf WH. N-acetyl-L-aspartic acid: a literature review of a compound prominent in 1H-NMR spectroscopic studies of brain. Neurosci Biobehav Rev. 1989; 13:23-31. [PubMed: 2671831]

22. Stanley JA. In vivo magnetic resonance spectroscopy and its application to neuropsychiatric disorders. Canadian Journal of Psychiatry Revue Canadienne de Psychiatrie. 2002; 47:315-326. [PubMed: 12025430]

23. Kreis R, Ernst T, Ross BD. Development of the human brain: in vivo quantification of metabolite and water content with proton magnetic resonance spectroscopy. Magn Reson Med. 1993; 30:424437. [PubMed: 8255190] 
24. Pettegrew JW, Klunk WE, Panchalingam K, McClure RJ, Stanley JA. Molecular insights into neurodevelopmental and neurodegenerative diseases. Brain research bulletin. 2000; 53:455-469. [PubMed: 11137004]

25. Goldstein G, Panchalingam K, McClure RJ, Stanley JA, Calhoun VD, Pearlson GD, et al. Molecular neurodevelopment: an in vivo 31P-1H MRSI study. J Int Neuropsychol Soc. 2009; 15:671-683. [PubMed: 19674503]

26. Horska A, Kaufmann WE, Brant LJ, Naidu S, Harris JC, Barker PB. In vivo quantitative proton MRSI study of brain development from childhood to adolescence. Journal of magnetic resonance imaging : JMRI. 2002; 15:137-143. [PubMed: 11836768]

27. Stanley JA, Vemulapalli M, Nutche J, Montrose DM, Sweeney JA, Pettegrew JW, et al. Reduced $\mathrm{N}$-acetyl-aspartate levels in schizophrenia patients with a younger onset age: a single-voxel $1 \mathrm{H}$ spectroscopy study. Schizophrenia Research. 2007; 93:23-32. [PubMed: 17498928]

28. Huttenlocher PR, de Courten C, Garey LJ, Van der Loos H. Synaptogenesis in human visual cortex--evidence for synapse elimination during normal development. Neurosci Lett. 1982; 33:247-252. [PubMed: 7162689]

29. Marsh R, Gerber AJ, Peterson BS. Neuroimaging studies of normal brain development and their relevance for understanding childhood neuropsychiatric disorders. J Am Acad Child Adolesc Psychiatry. 2008; 47:1233-1251. [PubMed: 18833009]

30. Pouwels PJ, Brockmann K, Kruse B, Wilken B, Wick M, Hanefeld F, et al. Regional age dependence of human brain metabolites from infancy to adulthood as detected by quantitative localized proton MRS. Pediatr Res. 1999; 46:474-485. [PubMed: 10509371]

31. Perlov E, Philipsen A, Matthies S, Drieling T, Maier S, Bubl E, et al. Spectroscopic findings in attention-deficit/hyperactivity disorder: review and meta-analysis. World J Biol Psychiatry. 2009; 10:355-365. [PubMed: 18609427]

32. da Silva Alves F, Boot E, Schmitz N, Nederveen A, Vorstman J, Lavini C, et al. Proton magnetic resonance spectroscopy in 22q11 deletion syndrome. PLoS One. 2011; 6:e21685. [PubMed: 21738766]

33. Brugger S, Davis JM, Leucht S, Stone JM. Proton magnetic resonance spectroscopy and illness stage in schizophrenia--a systematic review and meta-analysis. Biol Psychiatry. 2011; 69:495-503. [PubMed: 21145039]

34. Keshavan MSJA, Pettegrew JW. Magnetic resonance spectroscopy in schizophrenia: methodological issues and findings--part II. Biol Psychiatry. 2000; 48:369-380. [PubMed: 10978720]

35. Jessen F, Scherk H, Traber F, Theyson S, Berning J, Tepest R, et al. Proton magnetic resonance spectroscopy in subjects at risk for schizophrenia. Schizophr Res. 2006; 87:81-88. [PubMed: 16842971]

36. Keshavan MS, Dick RM, Diwadkar VA, Montrose DM, Prasad KM, Stanley JA. Striatal metabolic alterations in non-psychotic adolescent offspring at risk for schizophrenia: a (1)H spectroscopy study. Schizophrenia Research. 2009; 115:88-93. [PubMed: 19748228]

37. Davidson LL, Heinrichs RW. Quantification of frontal and temporal lobe brain-imaging findings in schizophrenia: a meta-analysis. Psychiatry Res. 2003; 122:69-87. [PubMed: 12714172]

38. Pantelis C, Velakoulis D, Wood SJ, Yucel M, Yung AR, Phillips LJ, et al. Neuroimaging and emerging psychotic disorders: the Melbourne ultra-high risk studies. Int Rev Psychiatry. 2007; 19:371-381. [PubMed: 17671870]

39. Wechsler, D. Wechsler adult intelligence scale- 4th Edition. San Antonio, Texas: The Psychological Corporation; 2008.

40. Wechsler, D. Intelligence Scale for Children-3rd Edition (WISC-III). San Antonio: The Psychological Corporation; 1999.

41. Wechsler D. Individual Achievement Test-II (WIAT-II). 2001

42. Chase-Carmichael CA, Ris MD, Weber AM, Schefft BK. Neurologic validity of the Wisconsin Card Sorting Test with a pediatric population. Clin Neuropsychol. 1999; 13:405-413. [PubMed: 10806452] 
43. Cornblatt BA, Risch NJ, Faris G, Friedman D, Erlenmeyer-Kimling L. The Continuous Performance Test, identical pairs version (CPT-IP): I. New findings about sustained attention in normal families. Psychiatry Res. 1988; 26:223-238. [PubMed: 3237915]

44. NIMH-CDISC. Computerized Diagnostic Interview Schedule for Children. 2004

45. Hall RC. Global assessment of functioning. A modified scale. Psychosomatics. 1995; 36:267-275. [PubMed: 7638314]

46. Klose U. In vivo proton spectroscopy in presence of eddy currents. Magn Reson Med. 1990; 14:26-30. [PubMed: 2161984]

47. Seeger U, Klose U, Mader I, Grodd W, Nagele T. Parameterized evaluation of macromolecules and lipids in proton MR spectroscopy of brain diseases. Magn Reson Med. 2003; 49:19-28. [PubMed: 12509816]

48. Provencher SW. Estimation of metabolite concentrations from localized in vivo proton NMR spectra. Magn Reson Med. 1993; 30:672-679. [PubMed: 8139448]

49. Smith SM, Jenkinson M, Woolrich MW, Beckmann CF, Behrens TE, Johansen-Berg H, et al. Advances in functional and structural MR image analysis and implementation as FSL. Neuroimage. 2004; 23(Suppl 1):S208-S219. [PubMed: 15501092]

50. Gasparovic C, Song T, Devier D, Bockholt HJ, Caprihan A, Mullins PG, et al. Use of tissue water as a concentration reference for proton spectroscopic imaging. Magn Reson Med. 2006; 55:12191226. [PubMed: 16688703]

51. Baslow MH. N-acetylaspartate in the vertebrate brain: metabolism and function. Neurochem Res. 2003; 28:941-953. [PubMed: 12718449]

52. Bhakoo KK, Pearce D. In vitro expression of $\mathrm{N}$-acetyl aspartate by oligodendrocytes: implications for proton magnetic resonance spectroscopy signal in vivo. J Neurochem. 2000; 74:254-262. [PubMed: 10617127]

53. Urenjak J, Williams SR, Gadian DG, Noble M. Proton nuclear magnetic resonance spectroscopy unambiguously identifies different neural cell types. J Neurosci. 1993; 13:981-989. [PubMed: 8441018]

54. Chakraborty G, Mekala P, Yahya D, Wu G, Ledeen RW. Intraneuronal N-acetylaspartate supplies acetyl groups for myelin lipid synthesis: evidence for myelin-associated aspartoacylase. $\mathrm{J}$ Neurochem. 2001; 78:736-745. [PubMed: 11520894]

55. Levitt P. Structural and functional maturation of the developing primate brain. The Journal of pediatrics. 2003; 143:S35-S45. [PubMed: 14597912]

56. Chang L, Friedman J, Ernst T, Zhong K, Tsopelas ND, Davis K. Brain metabolite abnormalities in the white matter of elderly schizophrenic subjects: implication for glial dysfunction. Biol Psychiatry. 2007; 62:1396-1404. [PubMed: 17693392]

57. Schaer M, Debbane M, Bach Cuadra M, Ottet MC, Glaser B, Thiran JP, et al. Deviant trajectories of cortical maturation in 22q11.2 deletion syndrome (22q11DS): A cross-sectional and longitudinal study. Schizophr Res. 2009

58. Shaw P, Gogtay N, Rapoport J. Childhood psychiatric disorders as anomalies in neurodevelopmental trajectories. Hum Brain Mapp. 2010; 31:917-925. [PubMed: 20496382]

59. Kates WR, Burnette CP, Bessette BA, Folley BS, Strunge L, Jabs EW, et al. Frontal and caudate alterations in velocardiofacial syndrome (deletion at chromosome 22q11.2). J Child Neurol. 2004; 19:337-342. [PubMed: 15224707]

60. Barnea-Goraly N, Menon V, Krasnow B, Ko A, Reiss A, Eliez S. Investigation of white matter structure in velocardiofacial syndrome: a diffusion tensor imaging study. Am J Psychiatry. 2003; 160:1863-1869. [PubMed: 14514502]

61. Campbell LE, Daly E, Toal F, Stevens A, Azuma R, Catani M, et al. Brain and behaviour in children with 22q11.2 deletion syndrome: a volumetric and voxel-based morphometry MRI study. Brain. 2006; 129:1218-1228. [PubMed: 16569671]

62. Courvoisie H, Hooper SR, Fine C, Kwock L, Castillo M. Neurometabolic functioning and neuropsychological correlates in children with ADHD-H: preliminary findings. J Neuropsychiatry Clin Neurosci. 2004; 16:63-69. [PubMed: 14990761] 
63. Fayed N, Modrego PJ. Comparative study of cerebral white matter in autism and attention-deficit/ hyperactivity disorder by means of magnetic resonance spectroscopy. Acad Radiol. 2005; 12:566569. [PubMed: 15866128]

64. Fayed N, Modrego PJ, Castillo J, Davila J. Evidence of brain dysfunction in attention deficithyperactivity disorder: a controlled study with proton magnetic resonance spectroscopy. Acad Radiol. 2007; 14:1029-1035. [PubMed: 17707309]

65. Shaw ME, Moores KA, Clark RC, McFarlane AC, Strother SC, Bryant RA, et al. Functional connectivity reveals inefficient working memory systems in post-traumatic stress disorder. Psychiatry Research. 2009; 172:235-241. [PubMed: 19398308]

66. Shaw P, Eckstrand K, Sharp W, Blumenthal J, Lerch JP, Greenstein D, et al. Attention-deficit/ hyperactivity disorder is characterized by a delay in cortical maturation. Proc Natl Acad Sci U S A. 2007; 104:19649-19654. [PubMed: 18024590] 

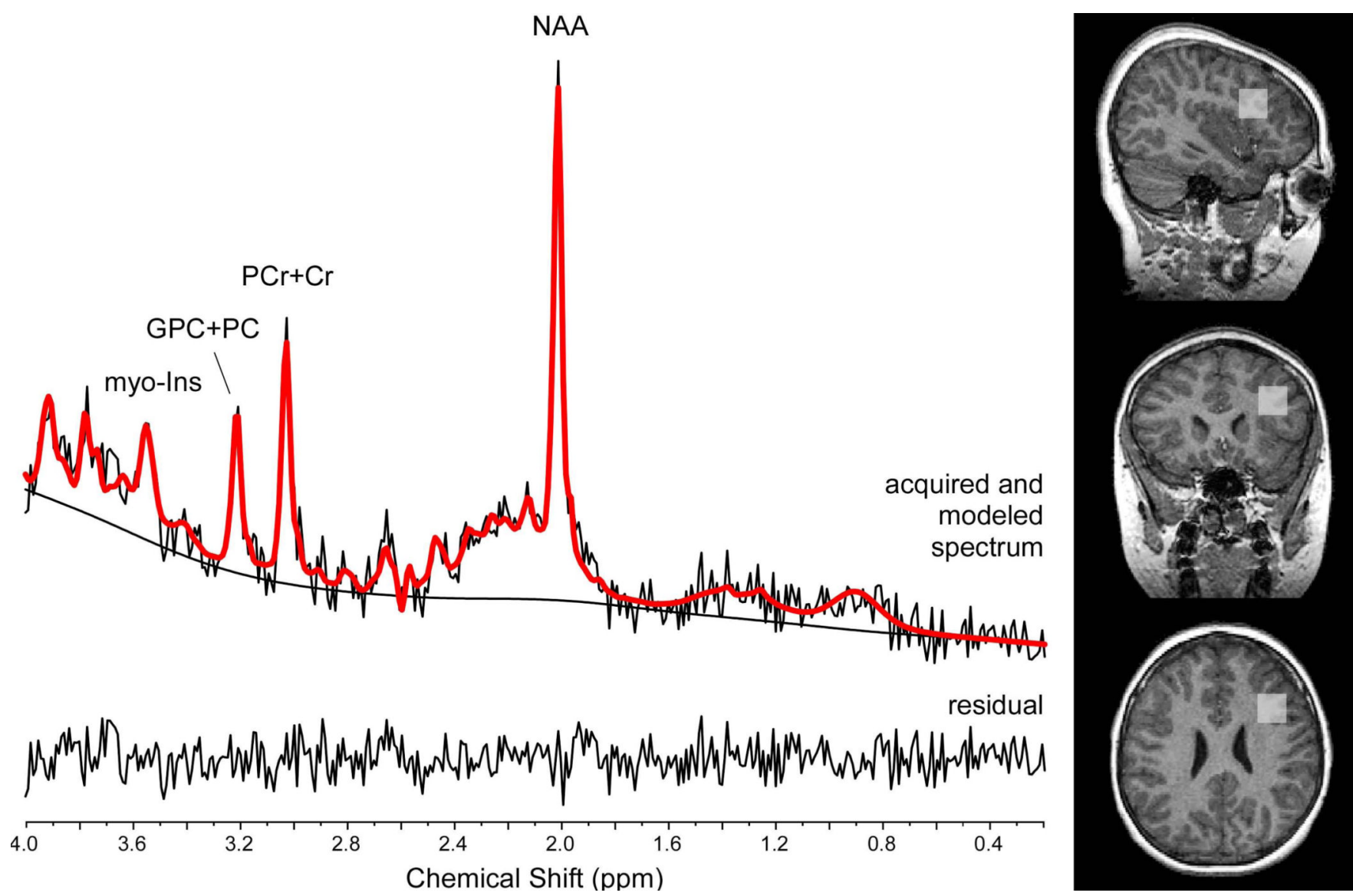

Figure 1.

A typical ${ }^{1} \mathrm{H}-\mathrm{MRS}$ spectrum is illustrated along with voxel placement in the subjects. 


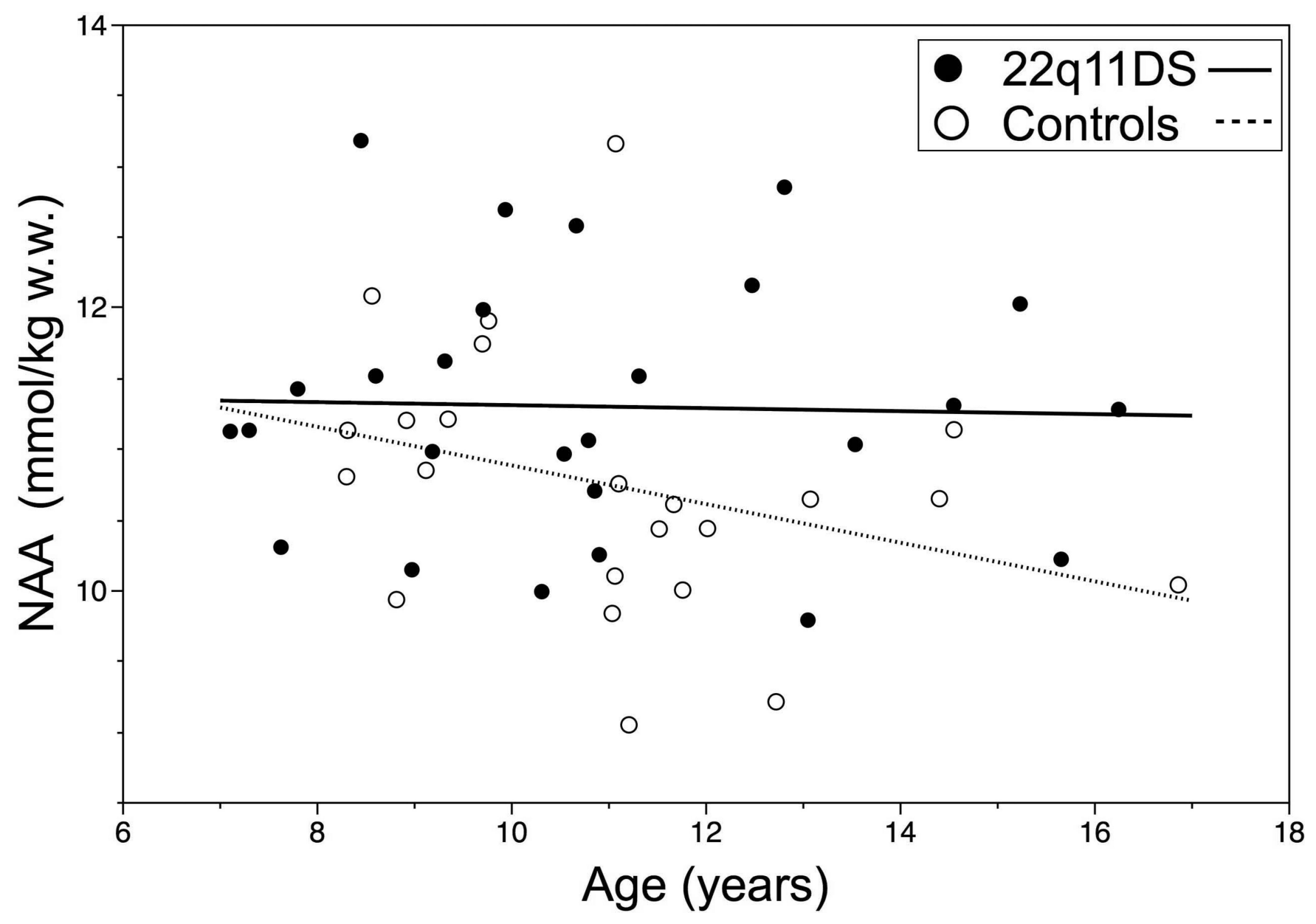

Figure 2.

The linear relation of NAA and age did not differ significantly between the two groups, although there was a trend toward lower levels with age in the control group $(r=-0.32)$ not seen in the 22q11DS group $(r=-0.030)$. 


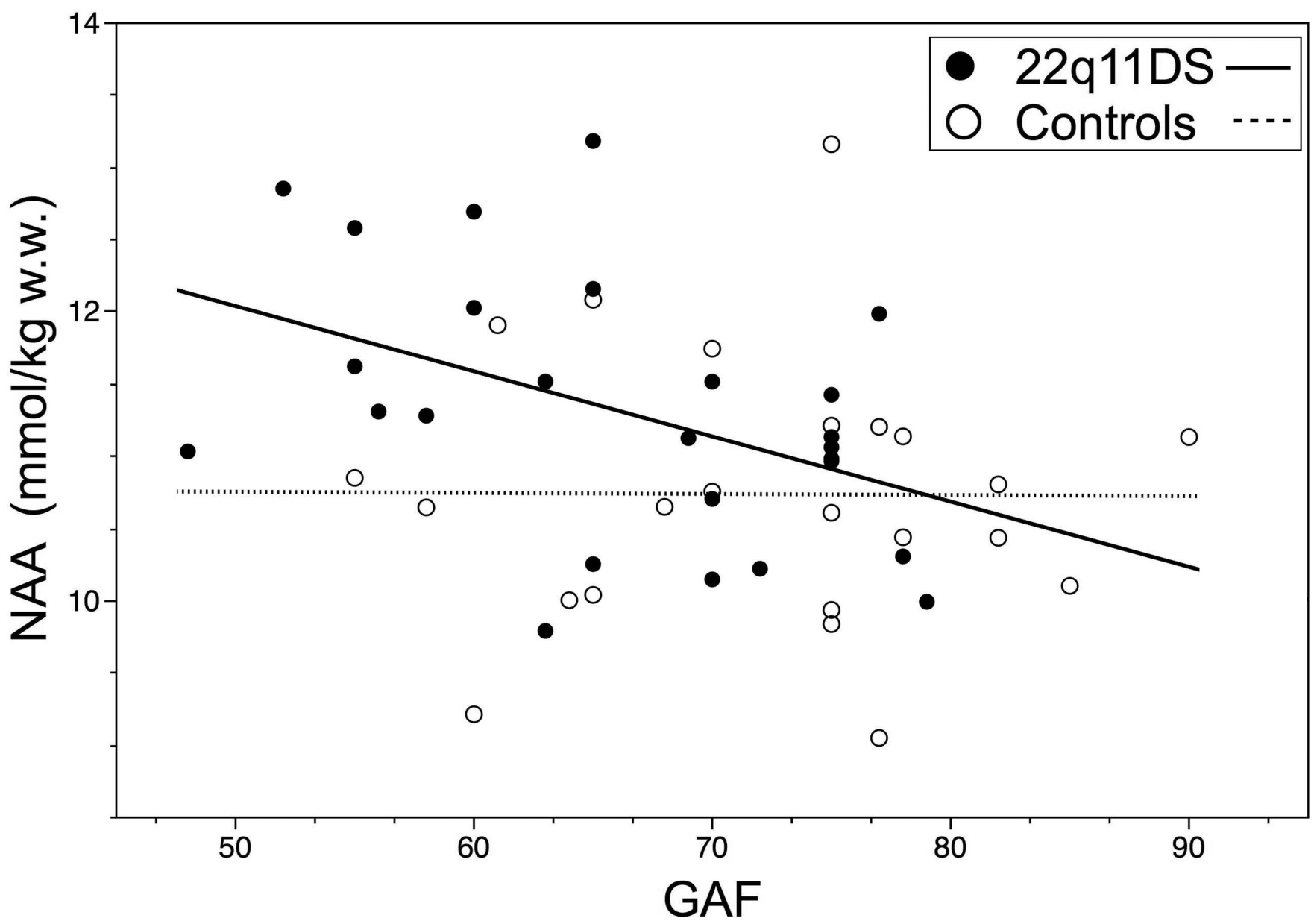

Figure 3.

Scatter plots demonstrating the correlation between GAF and NAA in children with 22q11DS and control subjects: NAA has a strong correlation with GAF in the 22q11DS group and this is not present in the control subjects. (Group $1=22$ q11DS; Group $2=$ Controls) 


\section{Table 1}

Abnormalities in neuropsychological functioning in children with 22q11DS, compared to matched control subjects

\begin{tabular}{|c|c|c|c|c|}
\hline Test & Group & Number & Mean (SD) & t statistic \\
\hline GAF & $\begin{array}{l}\text { 22q11DS } \\
\text { Controls }\end{array}$ & $\begin{array}{l}26 \\
23\end{array}$ & $\begin{array}{l}66.3(8.8) \\
71.7(9.3)\end{array}$ & $-2.07^{*}$ \\
\hline WISC Verbal Comprehension & $\begin{array}{l}22 \mathrm{q} 11 \mathrm{DS} \\
\text { Controls }\end{array}$ & $\begin{array}{l}25 \\
23\end{array}$ & $\begin{array}{l}75.0(8.8) \\
103.1(14.0)\end{array}$ & $-8.35^{* * *}$ \\
\hline WISC Perceptual Organization & $\begin{array}{l}22 q 11 D S \\
\text { Controls }\end{array}$ & $\begin{array}{l}25 \\
23\end{array}$ & $\begin{array}{l}77.0(10.1) \\
104.3(14.2)\end{array}$ & $-7.6^{* * *}$ \\
\hline WISC Working Memory & $\begin{array}{l}22 q 11 D S \\
\text { Controls }\end{array}$ & $\begin{array}{l}25 \\
23\end{array}$ & $\begin{array}{l}83.2(12.2) \\
103.3(12.8)\end{array}$ & $-5.53^{* *}$ \\
\hline WISC Processing Speed & $\begin{array}{l}22 q 11 D S \\
\text { Controls }\end{array}$ & $\begin{array}{l}25 \\
23\end{array}$ & $\begin{array}{l}78.2(12.7) \\
99.2(11.8)\end{array}$ & $-5.9^{* * *}$ \\
\hline WIAT Broad Reading & $\begin{array}{l}22 \mathrm{q} 11 \mathrm{DS} \\
\text { Controls }\end{array}$ & $\begin{array}{l}25 \\
23\end{array}$ & $\begin{array}{l}81.3(14.1) \\
101.2(15.1)\end{array}$ & $-4.8^{* * *}$ \\
\hline WIAT Broad Mathematics & $\begin{array}{l}22 q 11 D S \\
\text { Controls }\end{array}$ & $\begin{array}{l}18 \\
22\end{array}$ & $\begin{array}{l}76.1(18.3) \\
103.09(14.21)\end{array}$ & $-5.23^{* * *}$ \\
\hline WCST Perseverative Errors & $\begin{array}{l}\text { 22q11DS } \\
\text { Controls }\end{array}$ & $\begin{array}{l}26 \\
23\end{array}$ & $\begin{array}{l}89.8(11.7) \\
102.61(14.7)\end{array}$ & $-3.14^{* *}$ \\
\hline CPT AX Sustained Attention & $\begin{array}{l}22 q 11 D S \\
\text { Controls }\end{array}$ & $\begin{array}{l}25 \\
23\end{array}$ & $\begin{array}{l}1.54(1.17) \\
2.73(1.21)\end{array}$ & $-3.37^{* *}$ \\
\hline CPT IP Sustained Attention & $\begin{array}{l}22 q 11 D S \\
\text { Controls }\end{array}$ & $\begin{array}{l}25 \\
23\end{array}$ & $\begin{array}{l}.46(.53) \\
1.25(.76)\end{array}$ & $-4.19^{* *}$ \\
\hline DISC Anxiety Disorders & $\begin{array}{l}22 q 11 D S \\
\text { Controls }\end{array}$ & $\begin{array}{l}26 \\
23\end{array}$ & $\begin{array}{l}10 / 26 \\
1 / 23\end{array}$ & Fisher's exact test $\mathrm{p}<.01$ \\
\hline DISC ADHD & $\begin{array}{l}\text { 22q11DS } \\
\text { Controls }\end{array}$ & $\begin{array}{l}26 \\
23\end{array}$ & $\begin{array}{l}8 / 26 \\
6 / 23\end{array}$ & Fisher's exact test NS \\
\hline \multicolumn{5}{|l|}{$\mathrm{p}<.05$} \\
\hline \multicolumn{5}{|l|}{ ** ${ }^{*}<.01$} \\
\hline p $<.001$ & & & & \\
\hline
\end{tabular}


Table 3

Relationship of NAA levels and neuropsychological findings in children with 22q11DS

\begin{tabular}{|l|l|}
\hline Dependent Measure & Pearson Correlation/t-test \\
\hline GAF & $\mathbf{- 0 . 4 3 7 ^ { * }}$ \\
\hline DISC Inattention Symptoms & 0.156 \\
\hline DISC Hyperactive Symptoms & 0.16 \\
\hline DISC Any Diagnosis & 0.035 \\
\hline WISC -Verbal Comprehension Factor & 0.116 \\
\hline WISC -Working Memory & -0.314 \\
\hline WISC-Perceptual Organization Factor & -0.019 \\
\hline WISC-Processing Speed Factor & -0.222 \\
\hline WIAT-Broad Reading & -0.151 \\
\hline WIAT-Broad Mathematics & -0.383 \\
\hline WCST Perseverative Errors & -0.076 \\
\hline CPT AX Sustained Attention & -0.072 \\
\hline CPT IP Sustained Attention & 0.128 \\
\hline DISC ADHD (NAA levels of subjects with and without ADHD) & $\mathrm{t}$ statistic $=-\mathbf{2 . 5 0}$ \\
\hline DISC Any Anxiety Disorder (NAA levels of subjects with and without anxiety disorder) & $\mathrm{t}$ statistic $=0.488$ \\
\hline *** $<<05$ & \\
\hline p 05 & \\
\hline
\end{tabular}

Effect size: $0.1=$ Small, $0.3=$ Moderate and $\searrow 0.5=$ Large. Moderate and large effect sizes are in bold. 